\title{
Study of Zinc Sulfide Concentrates by DTA, TGA, and X-Ray Analyses and Their Roasting in Fluidized Bed Furnace
}

\author{
B. S. Boyanov and A. B. Peltekov \\ University of Plovdiv, 24 Tsar Asen Street, 4000 Plovdiv, Bulgaria \\ Correspondence should be addressed to B. S. Boyanov; boyanb@uni-plovdiv.bg
}

Received 25 April 2013; Accepted 19 May 2013

Academic Editors: N. Menad and U. Ulusoy

Copyright (C) 2013 B. S. Boyanov and A. B. Peltekov. This is an open access article distributed under the Creative Commons Attribution License, which permits unrestricted use, distribution, and reproduction in any medium, provided the original work is properly cited.

\begin{abstract}
Bulgaria is a major producer of zinc in the Balkans (about 100,000 tons per year). The two zinc plants (KCM S.A., Plovdiv, and LZC S.A., Kardzhali) deliver the necessary raw materials from Bulgaria and abroad. But the zinc production at LZC Kardzhali for nearly a year has stopped. Turkey is a main producer of zinc sulfide concentrates from the Balkan countries. In this connection, an analysis of the delivered Turkish sulfide zinc concentrates is made through statistical processing of data about their chemical content. For the aim of processing them according to the classic hydrometallurgical scheme, studies are carried out using X-ray phase analysis as well as DTA and TGA. Providing optimal charge for roasting in fluid bed furnace (FBF) can be successfully done by using the WEBbased information system we have written, which calculates mixtures of different raw materials. The program system developed is illustrated by calculations of charges of 5 zinc concentrates from Turkey. The accomplishment of optimal mixing of concentrates and providing a stable mix composition for a long period of time is a task of primary importance in the technological process control in zinc hydrometallurgy.
\end{abstract}

\section{Introduction}

The world production of zinc during the last years experiences a shortage of enough quantity of quality zinc raw materials. Regardless of the fact that during the years 20062012 the production of primary zinc raw materials increased from $8839 \mathrm{~K}$ tons to $13604 \mathrm{~K}$ tons (increase percentage of $18.9 \%$ ) and forecast to increase to about $14000 \mathrm{kt}$ in 2013, the demand usually exceeds the supply on the world markets [14].

Despite the expected considerable increase of the global production of concentrates in 2013, it is anticipated that the world supply of primary zinc raw materials will remain insufficient. This is due to the continuing position of China as the chief importer of concentrates and to the expected increase in the global production of refined zinc. This follows as a consequence of the ever-increasing consumption of metal zinc, mainly in China, India, and Brazil $[3,5,6]$.

A major producer of zinc on the Balkans is Bulgaria (about 100000 tons per year) [2, 7]. Bulgarian zinc plants deliver a part of the necessary zinc sulfide concentrates from Bulgaria and the Balkan countries-Turkey, Romania, Greece, Serbia, and Macedonia (Figure 1). A part of primary raw materials is imported from Poland, Morocco, Peru, Canada, and others.

Turkey is a main producer of sulfide zinc concentrates (Figure 2) as well as a main consumer (Figure 3 ) in the Balkans.

The zinc concentrates supplied from Turkey are very important for the development of the zinc industry in Bulgaria. In this connection, the aim of the present study is to statistically process the data for the chemical content of sulfide zinc concentrates from Turkey and to characterize them through DTA, TGA, and X-ray phase analysis. The obtained results are to be related to the optimal charging for the aims of roasting in fluid bed furnaces.

\section{Experimental}

The origin of the studied five Turkish zinc sulfide concentrates is from different mines, and they have different chemical and mineralogical composition. 


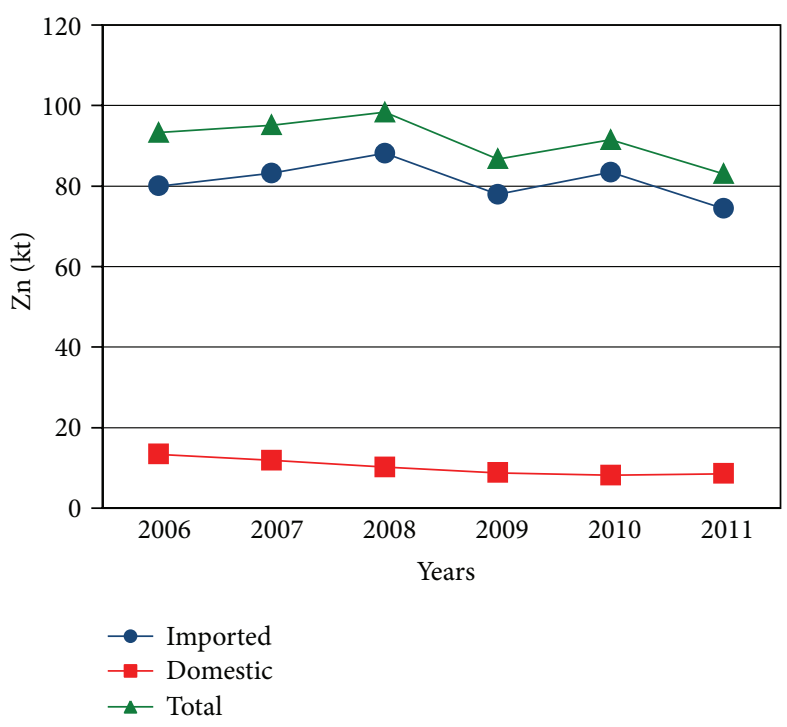

(a)

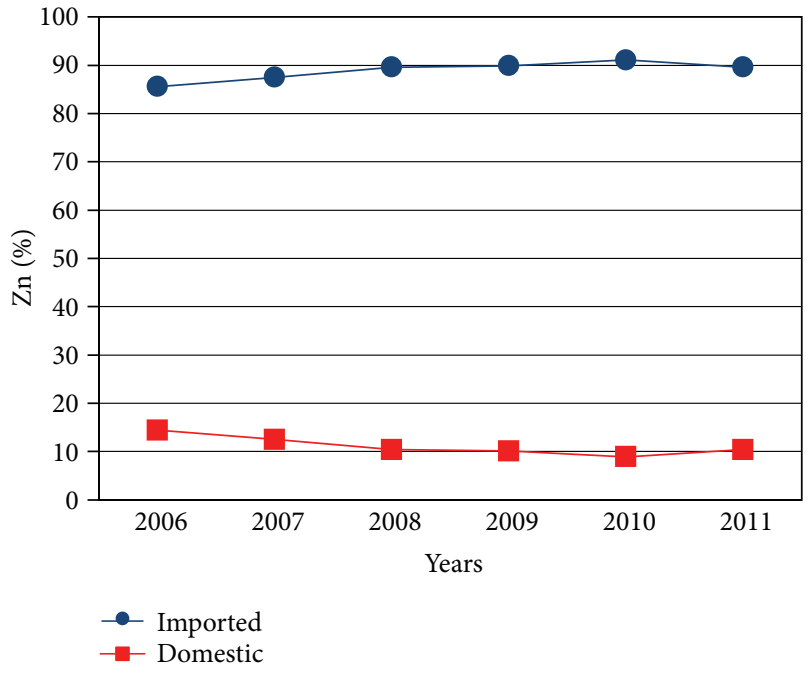

(b)

FIgURE 1: Processed zinc concentrates in Bulgaria in kt (a) and \% (b).

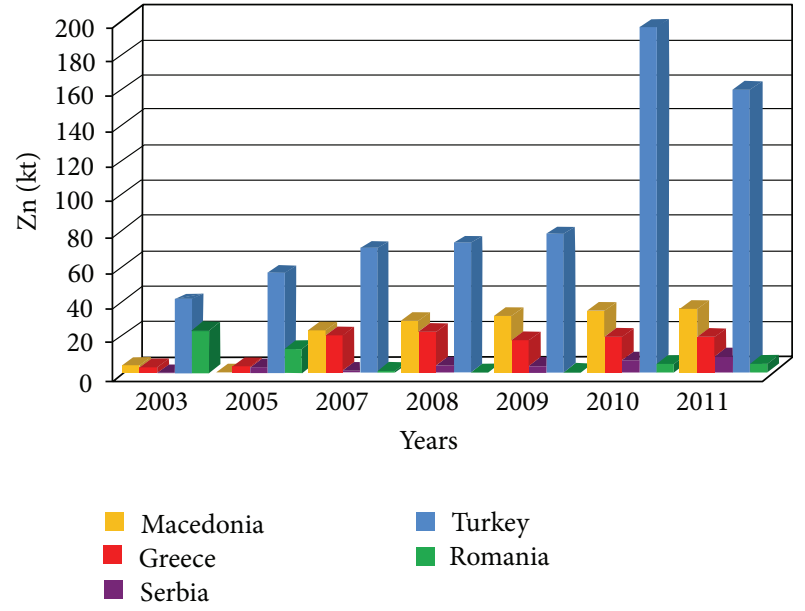

Figure 2: Zinc concentrates production from Balkan countries (except Bulgaria).

DTA and TGA (a Q Derivatograph, Hungary) were carried out under the following conditions: sensitivity of DTA, $0.5 \mathrm{mV}$; DTG, $1 \mathrm{mV}$; TG, $100 \mathrm{mg}$; heating rate, $10^{\circ} \mathrm{min}^{-1}$; and sample mass $100 \mathrm{mg}$. A ceramic crucible was used. All the studies were performed in air medium.

The X-ray phase analysis of the concentrates was carried out with an apparatus "TUR-M62" (Dresden, Germany) equipped with a computer-controlled HZG-4 goniometer with $\mathrm{Co}-\mathrm{K}_{\alpha}$ radiation and Bragg-Brentano geometry. Database (Powder Diffraction Files, Joint Committee on Powder Diffraction Standards, Philadelphia, PA, USA, 1997) was used for the phase identification.

A Web-based information system for calculation and prognosis of the chemical composition of the charges of concentrates is used as well as prognosis of chemical and

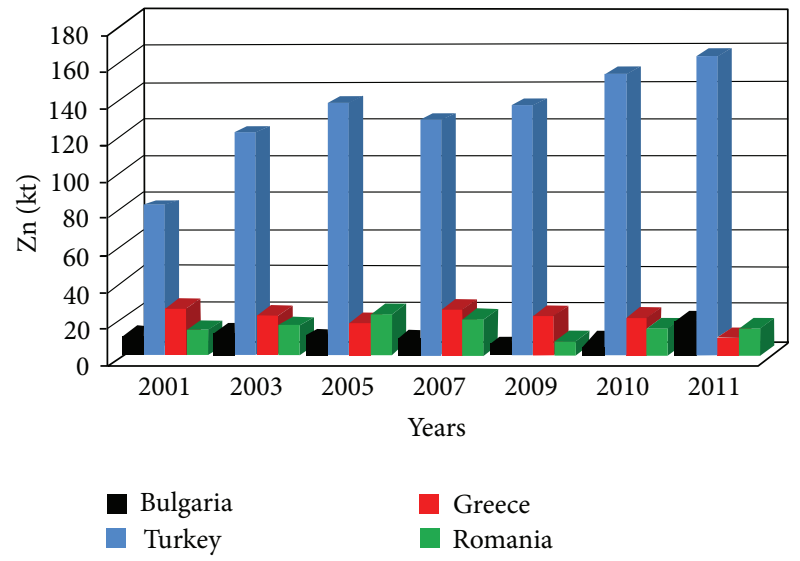

FIGURE 3: Data for consumers of metallic zinc in the Balkans.

phase composition of the zinc calcine obtained. It is built on a modular principle using server programming language PHP. Its main modules provide opportunities for construction, management, and use of Web-based database of zinc concentrates $[8,9]$ in the management control system relational database MySQL.

\section{Results and Discussion}

The contemporary zinc production uses pyrometallurgical and hydrometallurgical schemes $[10,11]$. Today the variants of the hydrometallurgical method play a major part with the production of over $80 \%$ of the world production of zinc.

Hydrometallurgical schemes for the production of zinc are used in Bulgaria [7]. The difference is mainly in the processing of the zinc cake. In KCM S.A., Plovdiv, a Waelz process is used, while in LZC S.A., Kardzhali, a jarosite process was recently applied [12]. 


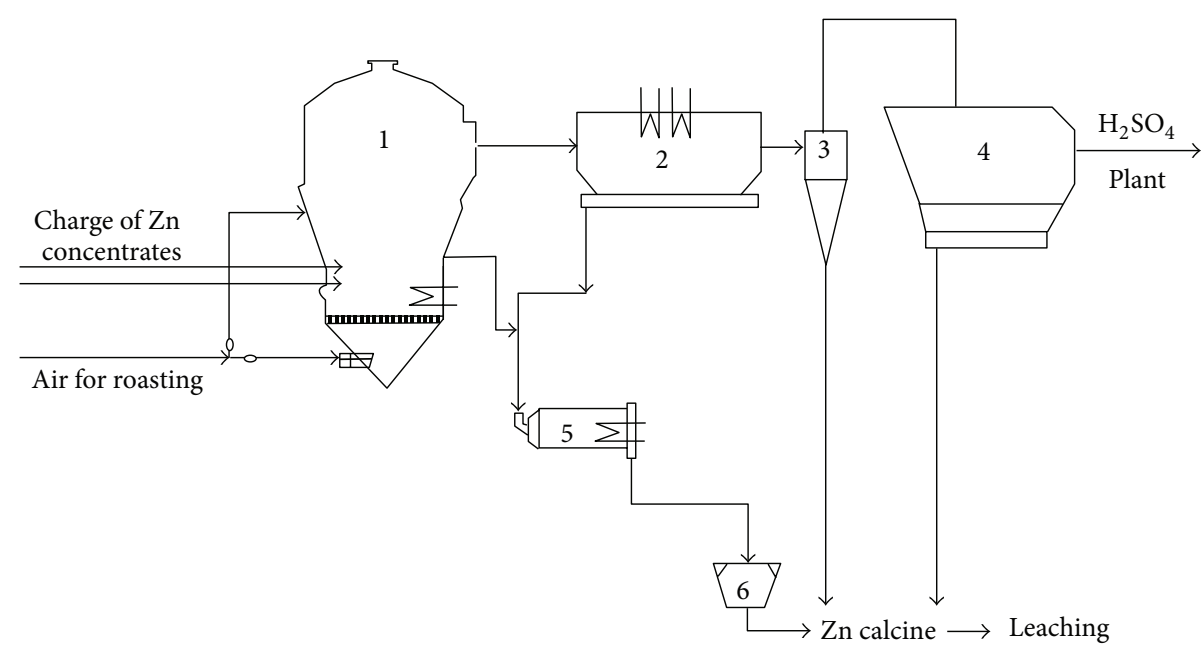

FIGURE 4: Technological scheme of roasting in fluidized bed: 1: fluid bed furnace; 2: waste heat boiler; 3: cyclone; 4: electrostatic precipitator; 5: roll cooler; 6: ball mill.

The process of roasting of zinc concentrates in KCM $\mathrm{AD}$, Plovdiv, is carried out in a fluidized bed furnace (FBF) of Lurgi company (Figure 4) with a floor area of $77 \mathrm{~m}^{2}$ (currently reduced to $68 \mathrm{~m}^{2}$ ). It is designed for the treatment of concentrates of different composition [3-5]. The resulting calcine has the following features on the sulfur content: $\mathrm{S}_{\mathrm{S}}-$ $0.3 \% \pm 0.1 \% ; \mathrm{SSO}_{4}-1.8 \% \pm 0.2 \%$. In LZC Kardzhali, an FBF with a classic cylindrical shape with a floor area $30 \mathrm{~m}^{2}$ worked until stopping the zinc production.

The zinc raw materials from storehouse with the necessary proportion are roasted in a fluid bed furnace. The furnace gases are cleaned of dust, $\mathrm{SO}_{2}$ is catalytically oxidized, and the obtained $\mathrm{SO}_{3}$ is absorbed, producing sulfuric acid.

The FBF zinc calcine, together with the dust from waste heat boiler, cyclones, and electrostatic precipitator, is leached with a sulfuric acid solution. The obtained $\mathrm{ZnSO}_{4}$ solution is purified of impurities ( $\mathrm{Fe}, \mathrm{Cu}, \mathrm{Cd}, \mathrm{Co}, \mathrm{Ni}, \mathrm{Cl}$, etc.) and is subjected to electrolysis. The obtained cathode zinc is melted to block zinc with SHG purity and is offered on the market.

The fluidized bed furnace (FBF) operation, as the main energetic and technological unit in the scheme of hydrometallurgical extraction of zinc, has a significant impact on the performance of the production process [1]. Its parameters depend on the technological regime, the structure of the FBF, and to a large extent on the nature of the processed raw materials [2].

In order to be able to control roasting in FBF more complete information is necessary about the influence of the concentrates and the products from their oxidation roasting on the indexes of the roasting process. The great difference in the chemical content of the concentrates and the presence of the marmatite mineral (nZnS.mFeS) are the basic factors influencing the whole technological process of zinc production $[13,14]$.

In order to be able to control roasting in FBF, more complete information is necessary about the influence of the concentrates and the products from their oxidation roasting [15] on the indexes of the roasting process. The great difference in the chemical content of the concentrates and the presence of the marmatite mineral are the basic factors influencing the whole technological process of zinc production [16].

The contemporary zinc production is characterized by concentrates differing in their chemical, mineralogical, phase, and granulometric content $[17,18]$. The data of over 130 chemical analyses of 18 components in supplied and used zinc concentrates from Turkey was processed. The obtained results (Figures 5 and 6 ) give the basis for the following general conclusions.

(1) The chemical content of the zinc concentrates shows that not all of them completely suit the demanded requirements for the composition of the basic and the impurity components.

(2) The data for the zinc (Figure 5(a)) show that most concentrates from Turkey meet the requirement for zinc content of over $50 \%$ (except for concentrate 2).

(3) To the requirement for a maximum value of $8 \% \mathrm{Fe}$ content in the concentrates, concentrate 2 does not correspond again (Figure 5(b)). At the same time all other concentrates have Fe content of about $5 \%$ or lower.

(4) Most of the concentrates do not meet the requirement for $\mathrm{Pb}$ content of less than $1.6 \%$ (Figure 5(c)). A content of $4-5 \% \mathrm{~Pb}$ (concentrates 1 and 3 ) is too high and dangerous for the carrying out of fluid bed roasting. This requires extreme attention when mixing the zinc concentrates with other imported raw materials in order to compensate for the high content of lead in the concentrates from Turkey and other countries from the Balkan peninsula.

(5) All Turkish concentrates have $\mathrm{SiO}_{2}$ content below $2.5 \%$ (Figure $5(\mathrm{~d})$ ). This is very favorable in connection with choosing a proper mix with low $\mathrm{SiO}_{2}$ content aiming to avoid the silicate formation.

(6) Most concentrates (except concentrate 2) meet the requirement for $\mathrm{Cu}$ content below 2.5\% (Figure 5(e)). 


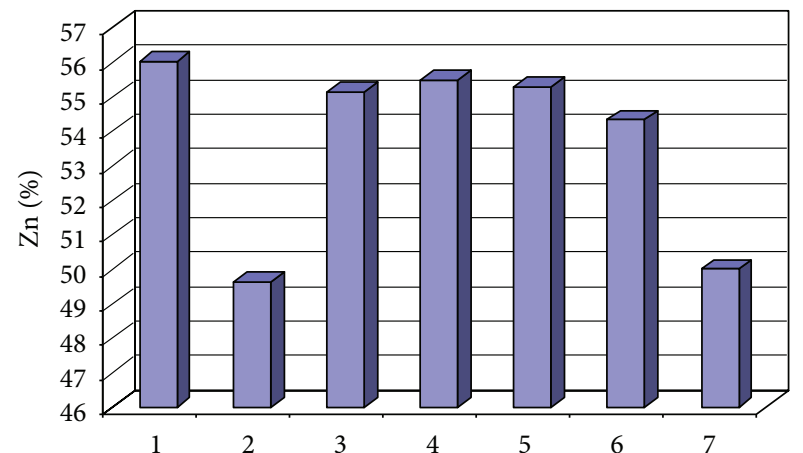

(a)

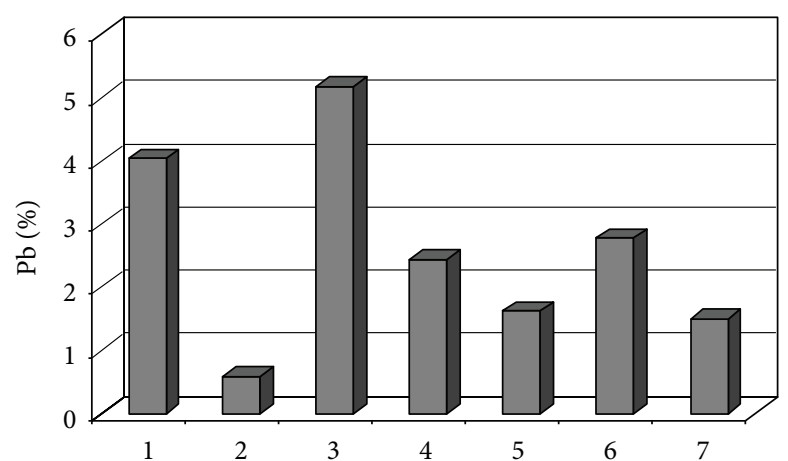

(c)

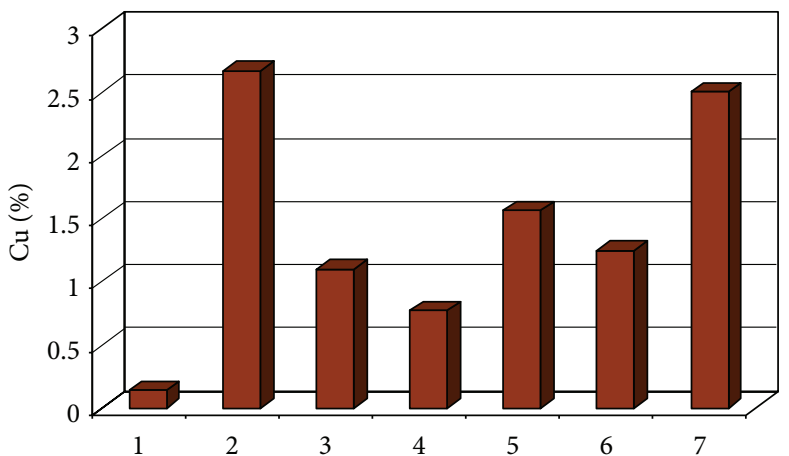

(e)

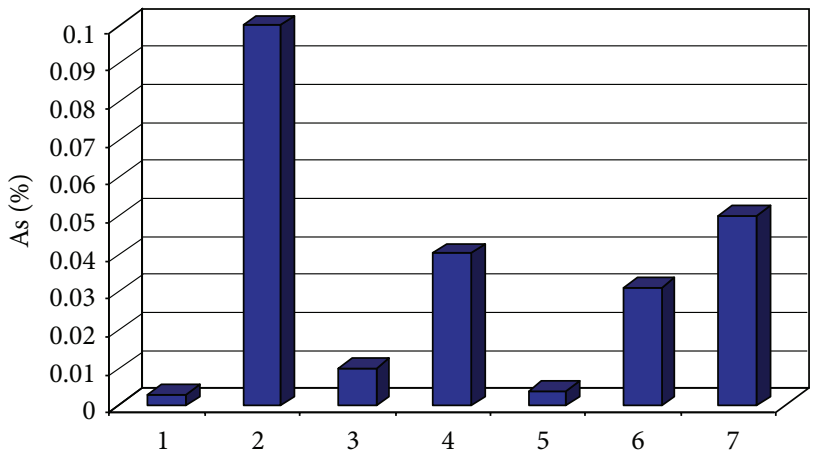

(g)

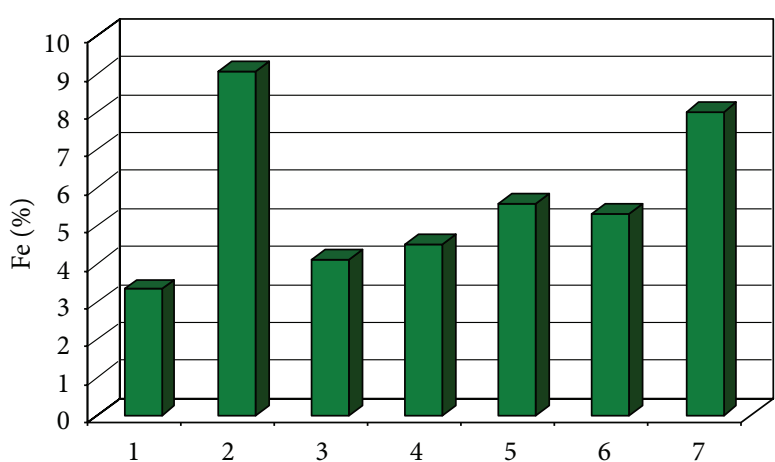

(b)

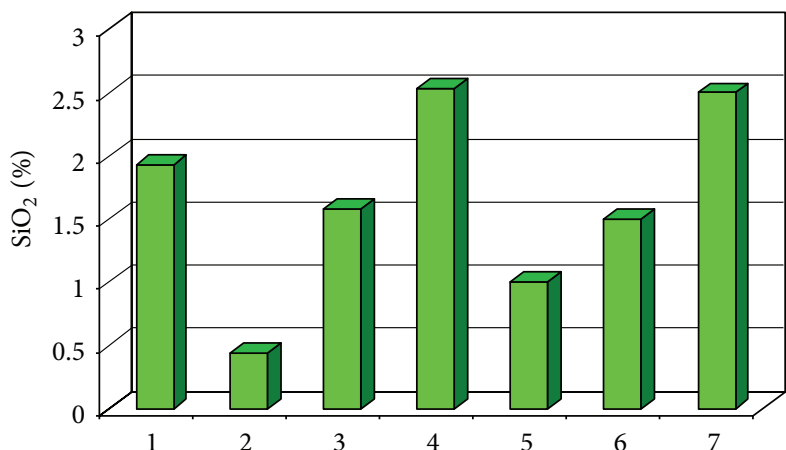

(d)

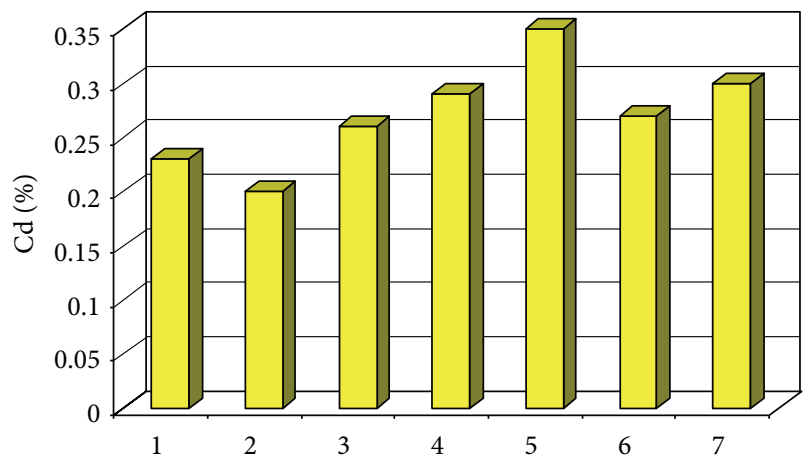

(f)

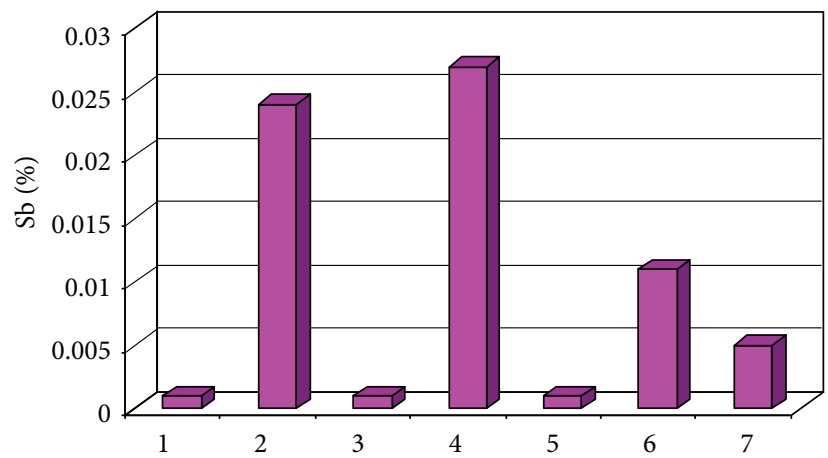

(h)

Figure 5: Content of $\mathrm{Zn}(\mathrm{a}), \mathrm{Fe}(\mathrm{b}), \mathrm{Pb}(\mathrm{c}), \mathrm{SiO}_{2}$ (d), $\mathrm{Cu}(\mathrm{e}), \mathrm{Cd}$ (f), $\mathrm{As}(\mathrm{g})$, and $\mathrm{Sb}$ (h) in the studied zinc sulfide concentrates (1-5); their average value (6); minimum admissible concentration of $\mathrm{Zn}$ and maximum admissible concentration for admixture elements (7) in concentrates. 


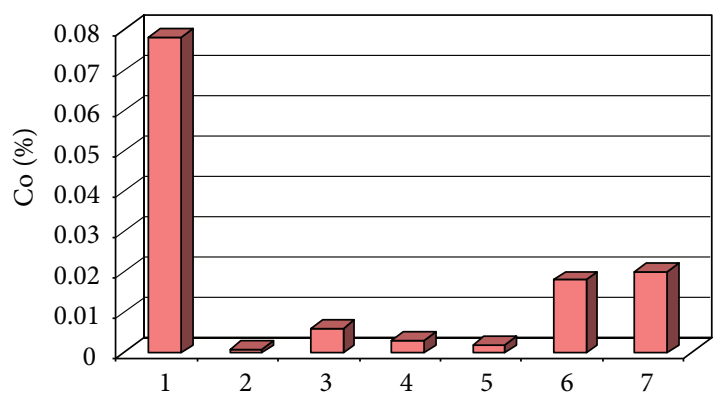

(a)

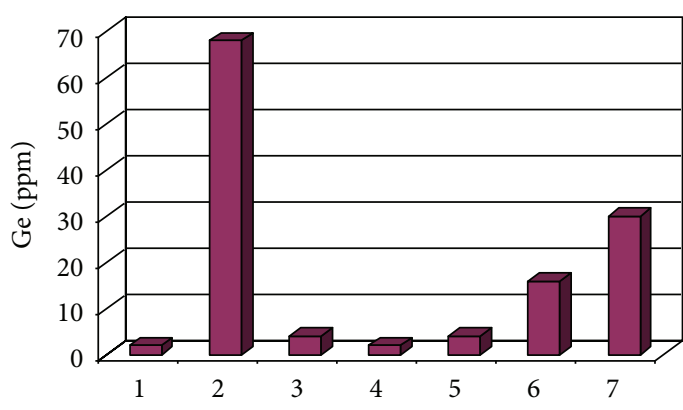

(c)

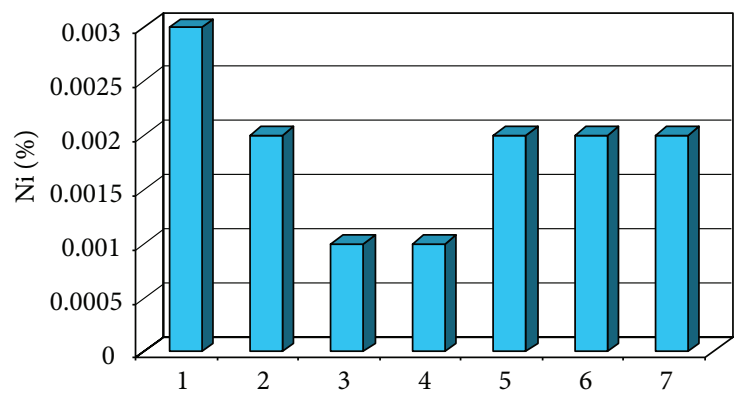

(b)

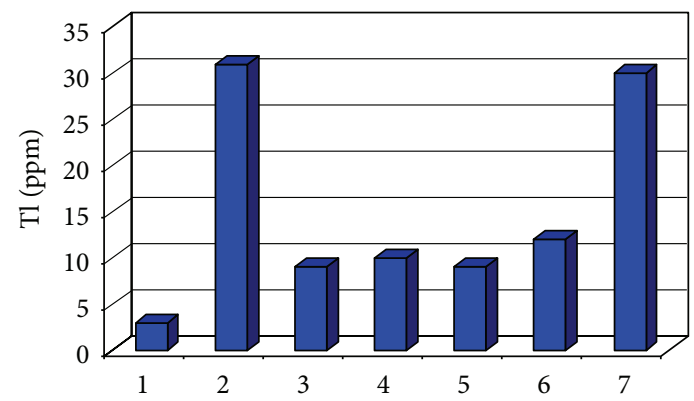

(d)

Figure 6: Content of Co (a), Ni (b), Ge (c), and $\mathrm{Tl}(\mathrm{d})$ in the studied zinc sulfide concentrates (1-5); their average value (6); maximum admissible concentration for admixture elements (7) in concentrates.

(7) Surpassing of the limit value of $0.3 \% \mathrm{Cd}$ is observed in concentrate 5, but it is not significant (Figure 5(f)).

(8) The admixture ions of As and $\mathrm{Sb}$ exert extremely harmful influence on the electroextraction of zinc. From the graphics in Figure 5(g) and Figure 5(h), it is clear that a part of zinc concentrates has As content below $0.05 \%$ and $\mathrm{Sb}$ content below $0.005 \%$. At the same time there are significant exceptions-for example, concentrate 2 does not meet the requirements for As content and concentrates 2 and 4 do not meet the requirements for $\mathrm{Sb}$ content. Proper mixing could decrease to a large degree this high Sb content in the obtained calcine, while at the same time it is necessary to carry out very carefully the hydrolysis purification of iron with the aim of maximum coprecipitation of antimony and arsenic.

(9) Concerning the Co and Ni content, significant deviations are observed in concentrate 1 (Figures 6(a) and 6(b)). Regarding the Ge content (Figure 6(c)), concentrate $2(68 \mathrm{ppm})$ significantly surpasses the maximum admissible value of $30 \mathrm{ppm}$. Regarding the content of $\mathrm{Tl}$ (Figure 6(d)), there is no big digression from the admissible limit concentration.

(10) With regard to the other components $(\mathrm{S}, \mathrm{Cl}, \mathrm{F}, \mathrm{CaO}$, $\mathrm{MgO}, \mathrm{Al}_{2} \mathrm{O}_{3}$, and $\mathrm{Hg}$ ) for which there are specific requirements for content, there are a few deviations in the zinc concentrates but they are not very large and could be overcome with mixing using mathematical methods.

The zinc sulfide concentrates are studied using X-ray phase analysis and the data are shown in Table 1.
In all concentrates, a basic phase is $\beta$-ZnS (sphalerite). The possible inclusion of a part of $\mathrm{ZnS}$ as marmatite (nZnS.mFeS) can be determined as a probability in two ways: by the intensity of the two most powerful lines of $\beta$-ZnS or by the types of the iron phases.

The obtained results from the X-ray phase analysis show that in the studied concentrates the six phases typical for all concentrates studied till now are basically observed: $\beta$-ZnS, nZnS.mFeS, $\mathrm{FeS}_{2}, \mathrm{CuFeS}_{2}, \mathrm{SiO}_{2}$ ( $\alpha$-quartz), and $\mathrm{PbS}$.

In terms of the roasting process, the greatest attention should be paid to the presence of $\mathrm{PbS}, \mathrm{CuFeS}_{2}$, and $\mathrm{FeS}_{2}$ in the concentrates, their oxidation [17-20], and interaction of obtained oxides with $\mathrm{SiO}_{2}$ because easily meltable lead-ironcopper silicates can be obtained.

A high degree of zinc leaching could be achieved at low iron content in the concentrates and especially at the absence of a marmatite phase.

This shows that the concentrates 1,2 , and 5 subjected to X-ray phase analysis will contribute to the obtaining of zinc ferrite insoluble in diluted $\mathrm{H}_{2} \mathrm{SO}_{4}$ solutions due to the presence of the marmatite phase in them $[14,16]$.

Differential-thermal studies have been conducted to characterize more thoroughly the studied zinc concentrates. In Figure 7 are shown the DTA, TGA, and DTG curves of one of the studied concentrates, and the generalized data taken from this study are presented in Table 2 .

Two temperature intervals at which exothermic effects take place are basically observed. The first, at a temperature interval of $460-480^{\circ} \mathrm{C}$, results from the oxidation of iron and copper sulfides $[14,16-20]$. This low-temperature exothermically effect is especially visible on the DTA curves of the most Turkish concentrates. The presence of this effect reveals 
TABLE 1: X-ray diffraction phase analysis of Turkish zinc sulfide concentrates.

\begin{tabular}{|c|c|c|c|c|c|}
\hline \multirow{2}{*}{ Number } & \multicolumn{5}{|c|}{ Concentrates/phases } \\
\hline & 1 & 2 & 3 & 4 & 5 \\
\hline (1) & $\beta-\mathrm{ZnS}$ & $\beta-\mathrm{ZnS}$ & $\beta-\mathrm{ZnS}$ & $\beta-\mathrm{ZnS}$ & $\beta-\mathrm{ZnS}$ \\
\hline (2) & (nZnS.mFeS) & (nZnS.mFeS) & & & (nZnS.mFeS) \\
\hline (3) & & $\mathrm{FeS}_{2}$ & $\mathrm{FeS}_{2}$ & $\mathrm{FeS}_{2}$ & \\
\hline (4) & $\mathrm{CuFeS}_{2}$ & $\mathrm{CuFeS}_{2}$ & $\mathrm{CuFeS}_{2}$ & & $\mathrm{CuFeS}_{2}$ \\
\hline (5) & $\begin{array}{c}\mathrm{SiO}_{2} \\
(\alpha \text {-quartz) }\end{array}$ & & & $\begin{array}{c}\mathrm{SiO}_{2} \\
(\alpha \text {-quartz })\end{array}$ & \\
\hline (6) & $\mathrm{PbS}$ & & $\mathrm{PbS}$ & $\mathrm{PbS}$ & $\mathrm{PbS}$ \\
\hline
\end{tabular}

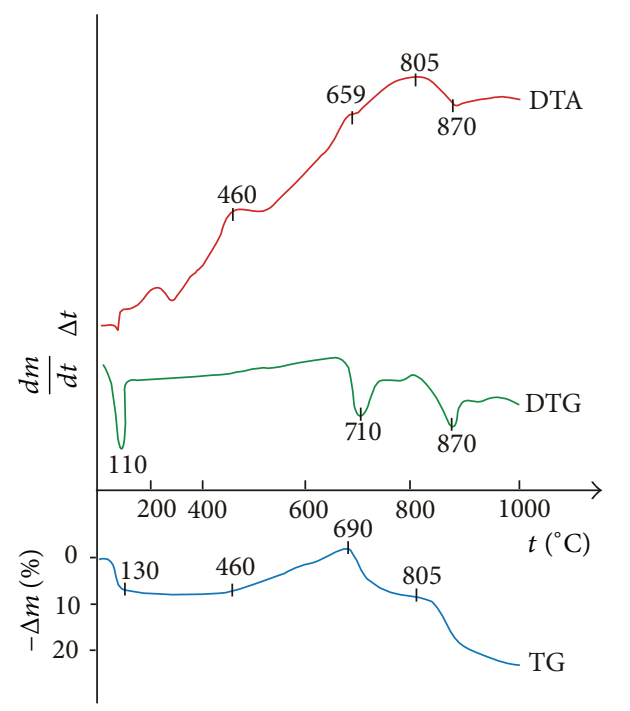

Figure 7: Typical DTA, TG, and DTG curves of zinc concentrate.

that independent phases of $\mathrm{Fe}$ and $\mathrm{Cu}$ exist in the studied concentrates.

The most intensive exothermic effects are obtained at $750-805^{\circ} \mathrm{C}$ due to the intensive oxidation of the zinc sulfide. Slight endothermic effects are observed at the temperature interval of $650-710^{\circ} \mathrm{C}$ that are due to the dissociation of the obtained $\mathrm{FeSO}_{4}$ and $\mathrm{CuSO}_{4}$.

The analysis of the obtained diagrams reports that the outlined exothermic effects at the $\mathrm{ZnS}$ oxidation are situated in a broader temperature interval. This could probably be due to two reasons: the finely granulated nature of the concentrates and the obtaining of a certain quantity of $\mathrm{ZnSO}_{4}$ that dissociates afterward.

As a result of the first reason, influence on the oxidation process exerts the counterstream diffusion of oxygen towards the inner layers of the sample and of sulfur dioxide-from the inside out towards the atmosphere. This process is connected with energy waste, which decreases the intensity of the oxidation highs.

The mass increase of the TGA curve at a temperature of about $670-695^{\circ} \mathrm{C}$ is due to the obtaining of $\mathrm{FeSO}_{4}$ and $\mathrm{CuSO}_{4}$. At temperature $805-830^{\circ} \mathrm{C}$ a new increase of the mass is visible, which is connected with the obtaining of $\mathrm{ZnSO}_{4}$.
TABLE 2: Results from DTA and TGA analysis of zinc concentrates.

\begin{tabular}{lccc}
\hline Concentrate & $\begin{array}{c}\text { Endothermic } \\
\text { effects at } t,{ }^{\circ} \mathrm{C}\end{array}$ & $\begin{array}{c}\text { Exothermic } \\
\text { effects at } t,{ }^{\circ} \mathrm{C}\end{array}$ & $\begin{array}{c}-\Delta m, \% \text { at } \\
1000^{\circ} \mathrm{C}\end{array}$ \\
\hline 1 & 875 & 750 & 17.0 \\
& 920 & 480 & \\
2 & 530 & 670 & 21.0 \\
& 710 & 750 & \\
3 & 890 & 470 & 21.4 \\
4 & 870 & 800 & \\
4 & & 680 & \\
& 880 & 800 & \\
5 & & 460 & 21.0 \\
& & 695 & \\
& & 805 &
\end{tabular}

The values of the mass change $(-\Delta m)$ at $1000^{\circ} \mathrm{C}$ for the different concentrates are comparatively similar.

The obtained data for the chemical, phase, and granulometric content of 5 different zinc concentrates from Turkey show a number of differences. Bearing in mind that they comprise a significant part of the zinc raw materials processed in Bulgaria, special attention should be paid to the possibly most thorough incoming control of the concentrates. The data for the chemical content are especially important for the carrying out of optimal mixing using mathematical methods $[8,9,21]$. The obtained information for the phase and granulometric content as well as the studies with DTA and TGA analysis is used to control and manage the complex processes taking place at the roasting of the concentrates in fluid bed. This helps to obtain gasses with the necessary $\mathrm{SO}_{2}$ content for the production of sulfuric acid and of zinc calcine suitable for processing according to one of the hydrometallurgical schemes for zinc production.

A Web-based expert system $[8,9]$ was used for calculating the optimal charges of the studied zinc concentrates from Turkey. The concentrate N1 was considered to be the optimizing one. The requirements for the chemical composition of the charge from sulfide zinc concentrates for roasting in a fluidized bed furnace are as follows: $\mathrm{Zn}>50 \%$; $\mathrm{S} 32 \pm 2 \%$; $\mathrm{Fe}<$ $8.0 \% ; \mathrm{Pb}<1.6 \% ; \mathrm{SiO}_{2}<2.30 \% ; \mathrm{Ge}<20 \mathrm{~g} / \mathrm{t} ; \mathrm{Sb}<0.01 \%$; As $<$ $0.06 \% ; \mathrm{MgO}<0.30 \% ; \mathrm{CaO}<0.50 \%$; and $\mathrm{F}<0.02 \%$.

The calculated charges of zinc concentrates that meet the specified requirements are 6 . They have zinc, soluble 
TABLE 3: Results from the calculation of zinc concentrate charges and chemical and phase composition of the best charge and prognostic calcine.

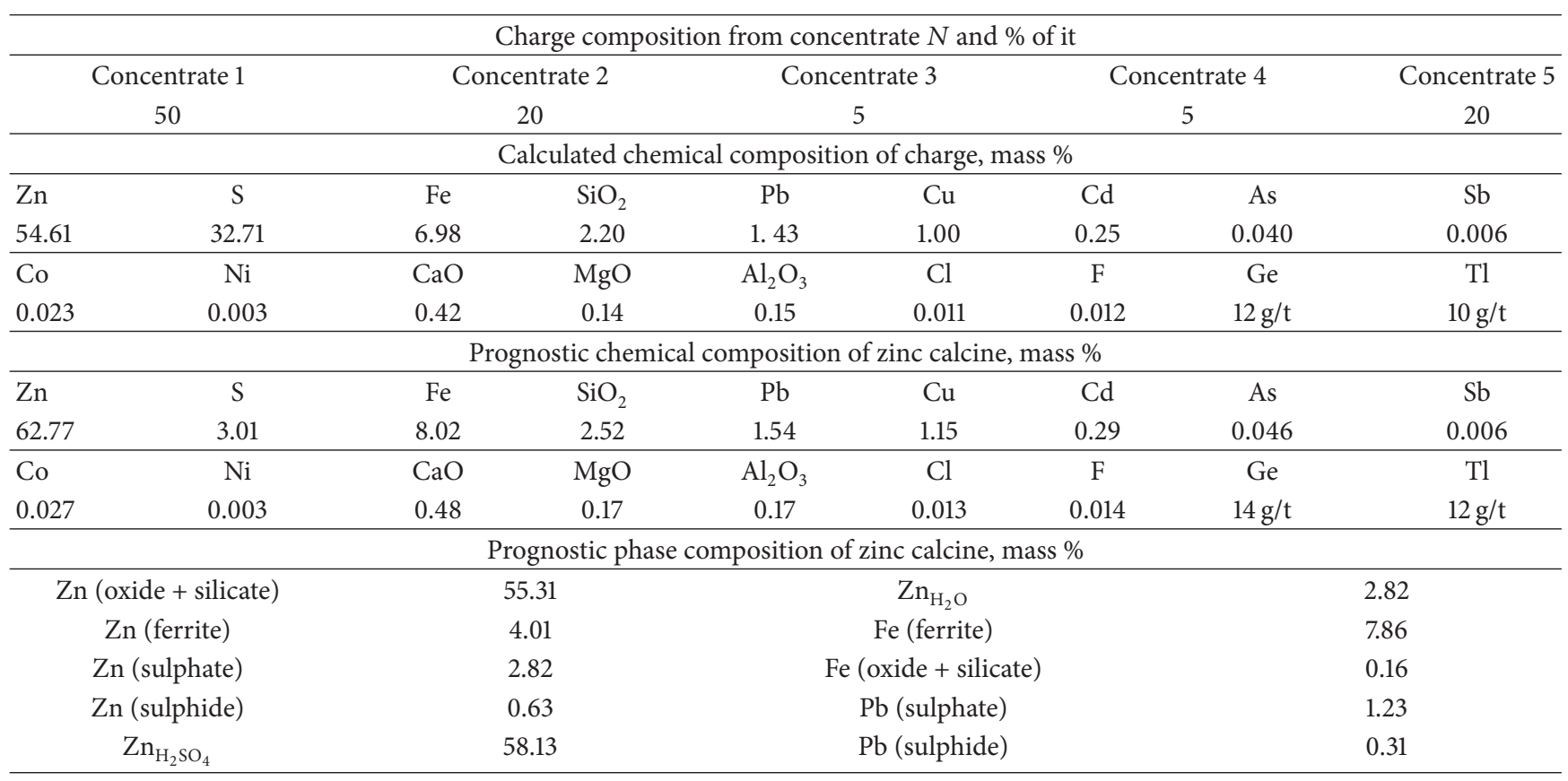

in $7 \%$ solution of sulfuric acid, in the range $92.14-92.60 \%$. This allows varying the choice of charge depending on the quantities of concentrates and their prices.

The best charge was obtained at the ratio of concentrates given in Table 3.

The results show that the use of the Web-based expert system gives very good results concerning composition of the charge and quality of the obtained calcine. The system also allows optimization on economic criteria, when the concentrate prices are known.

\section{Conclusion}

(1) Through using chemical, X-ray phase, DTA, and TGA analyses, a more thorough and detailed information for the processed zinc concentrates from Turkey is obtained.

(2) The presence of the following basic phases in zinc sulfide concentrates is established: $\beta-\mathrm{ZnS}, \mathrm{nZnS} . \mathrm{mFeS}$, $\mathrm{FeS}_{2}, \mathrm{CuFeS}_{2}, \mathrm{SiO}_{2}$ ( $\alpha$-quartz), and PbS.

(3) The behavior of the concentrates at thermal treatment up to $1000^{\circ} \mathrm{C}$ in air atmosphere is examined. The types and the temperature intervals of the observed oxidizing and dissociation processes are established.

(4) The calculations made show that when the concentrates are appropriately proportioned a mix with a very good chemical composition is obtained. This leads to a stable regime of oxidized roasting in fluid bed furnace, a constant in its chemical and phase content calcine, and good chemical-technological indexes of both roasting and leaching.

\section{Acknowledgment}

The sponsorship by the Bulgarian National Science Fund at the Ministry of Education, Youth and Science under Project FFNNIPO_12_00182/2012 is gratefully acknowledged.

\section{References}

[1] S. Wilkinson, "The zinc industry: challenges and opportunities," in Proceedings of the 4th International Conference ZINC, Plovdiv, Bulgaria, September 2006.

[2] N. Dobrev, "Zinc production in Bulgaria. State and perspectives," in Proceedings of the 4th International Conference ZINC, Plovdiv, Bulgaria, September 2006.

[3] Metalls Despatch, "Newsletter of the International Metals Study Groups," Issue No. 10, November 2010, http://www.insg.org/ \%5Cdocs\%5CMD10.pdf.

[4] International Lead and Zinc Study Group, http://www.ilzsg .org/static/statistics.aspx.

[5] P. White, "ZINC: funds, fundamentals of China," in Proceedings of the 4th International Conference ZINC, pp. 1135-1247, Plovdiv, Bulgaria, September 2006.

[6] P. R. Chandna, "Zinc metal industry in India," in Proceedings of the 4th International Conference ZINC, p. 49, Plovdiv, Bulgaria, September 2006.

[7] N. Dobrev and A. Shukerov, "The outlook for the Bulgarian lead and zinc sector," in Proceedings of the 55th Annual Session of ILZSG, Lisbon, Portugal, October 2010, http://www.ilzsg.org/ generic/pages/list.aspx?table=document\&ff_aa_document_type $=\mathrm{P} \&$ from $=1$.

[8] B. S. Boyanov, M. P. Sandalski, and K. I. Ivanov, "Zinc sulfide concentrates and optimization of their roasting in fluidezed bed reactor," World Academy of Science, Engineering and Technology, vol. 73, pp. 326-332, 2011. 
[9] M. P. Sandalski, B. S. Boyanov, P. G. Georgiev, and A. K. Sotirov, "Web based expert system optimization for processes in chemical technology," in Proceedings of 42nd International October Conference of Mining and Metallurgy, pp. 569-572, Kladovo, Serbia, October 2010.

[10] F. Habashi, "Recent trends in extractive metallurgy," Journal of Mining and Metallurgy, Section B, vol. 45, no. 1, pp. 1-13, 2009.

[11] Y. Umetsu, "Advances and challenges in zinc production," in International Symposium on Lead \& Zinc Production, pp. 89101, Kyioto, Japan, October 2005.

[12] P. Lessidrenski, I. Gruev, A. Apostolov, S. Stoyanova, and E. Bekrieva, "Jarosite technology for zinc production at the lead and zinc complex and optimization of the reagent mode," in Proceedings of the 4th International Conference ZINC, pp. 213216, Plovdiv, Bulgaria, September 2006.

[13] S. Kharbish, "A Raman spectroscopic investigation of Fe-rich sphalerite: effect of fe-substitution," Physics and Chemistry of Minerals, vol. 34, no. 8, pp. 551-558, 2007.

[14] B. S. Boyanov, R. I. Dimitrov, and Ž. D. Živkovíc, “Thermal behaviour of low-quality zinc sulphide concentrate," Thermochimica Acta, vol. 296, no. 1-2, pp. 123-128, 1997.

[15] J. C. Balarini, L. D. O. Polli, T. L. S. Miranda, R. M. Z. D. Castro, and A. Salum, "Importance of roasted sulphide concentrates characterization in the hydrometallurgical extraction of zinc," Minerals Engineering, vol. 21, no. 1, pp. 100-110, 2008.

[16] B. S. Boyanov and N. K. Kolev, "Characteristics and roasting of sulphide zinc concentrates in fluid bed roaster," in Proceedings of the 4th International Conference ZINC, pp. 275-288, Plovdiv, Bulgaria, September 2006.

[17] Ž. D. Živković, N. Mitevska, and V. Savović, "Kinetics and mechanism of the chalcopyrite-pyrite concentrate oxidation process," Thermochimica Acta, vol. 282-283, pp. 121-130, 1996.

[18] Ž. D. Živković, N. Milosavljević, and J. Šesták, "Kinetics and mechanism of pyrite oxidation," Thermochimica Acta, vol. 157, no. 2, pp. 215-219, 1990.

[19] J. G. Dunn, “The oxidation of sulphide minerals," Thermochimica Acta, vol. 300, no. 1-2, pp. 127-139, 1997.

[20] N. Strabac, D. Zivkovic, Ž. D. Živković, and I. Mihajlovic, Sulfidi-termijska, termodinamicka $i$ kineticka analiza, Technical Faculty of Bor, University of Belgrade, 2005.

[21] B. Boyanov, M. Sandalski, and R. Dimitrov, "Software for optimising the mixing proportions of polycomponent raw materials," Bulgarian Chemistry and Industry, vol. 71, no. 1, pp. 10-13, 2000. 

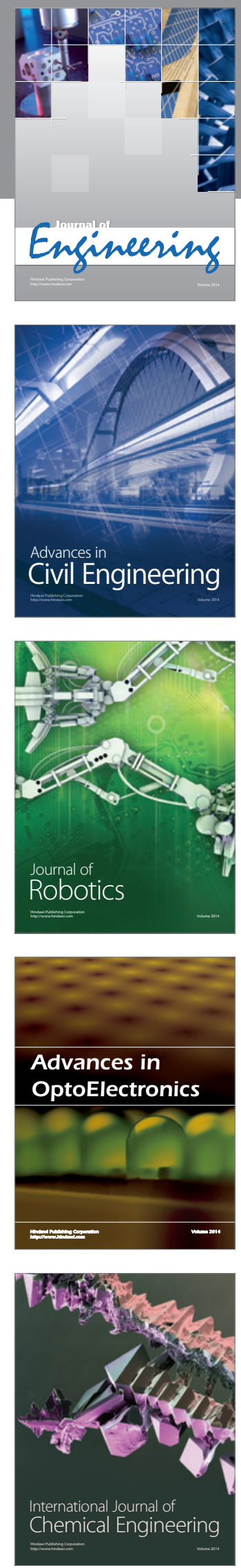

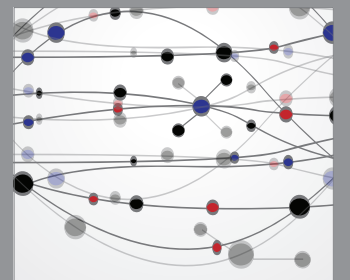

The Scientific World Journal
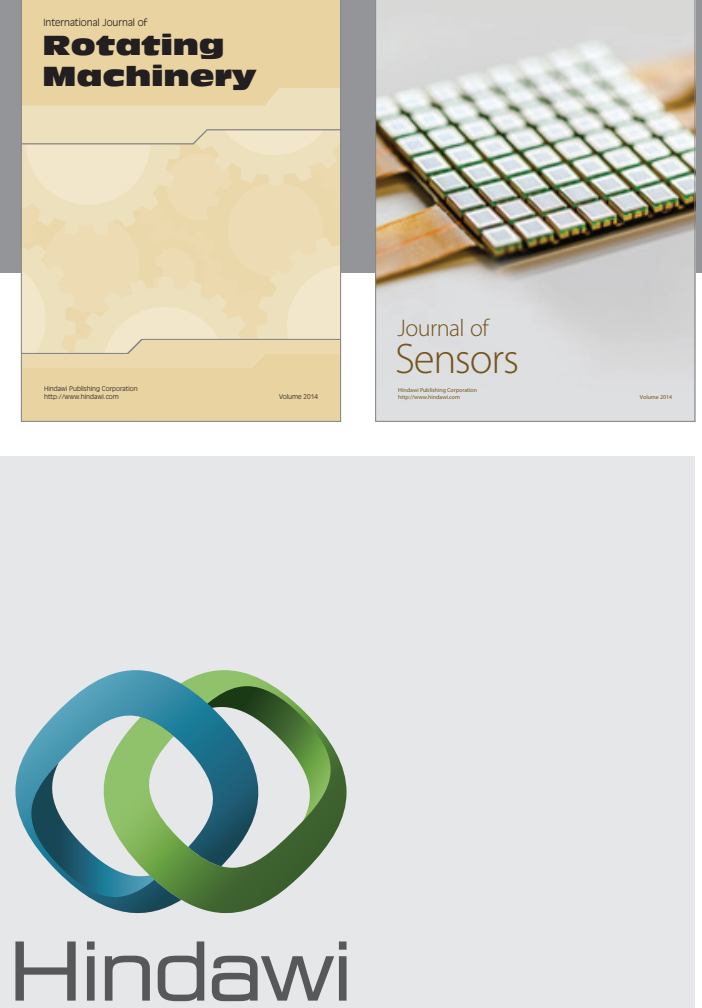

Submit your manuscripts at http://www.hindawi.com
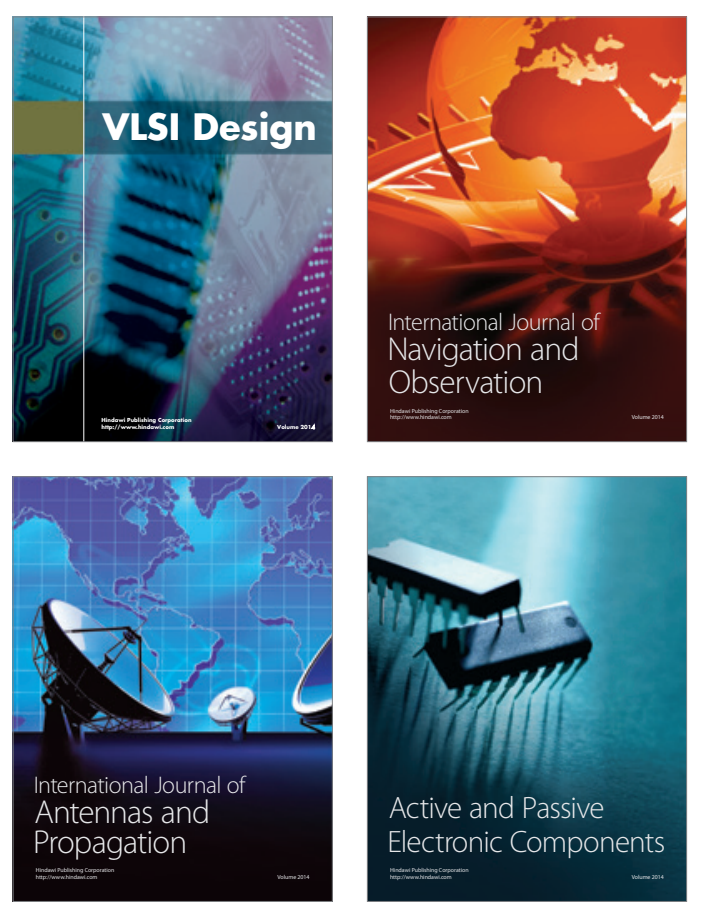
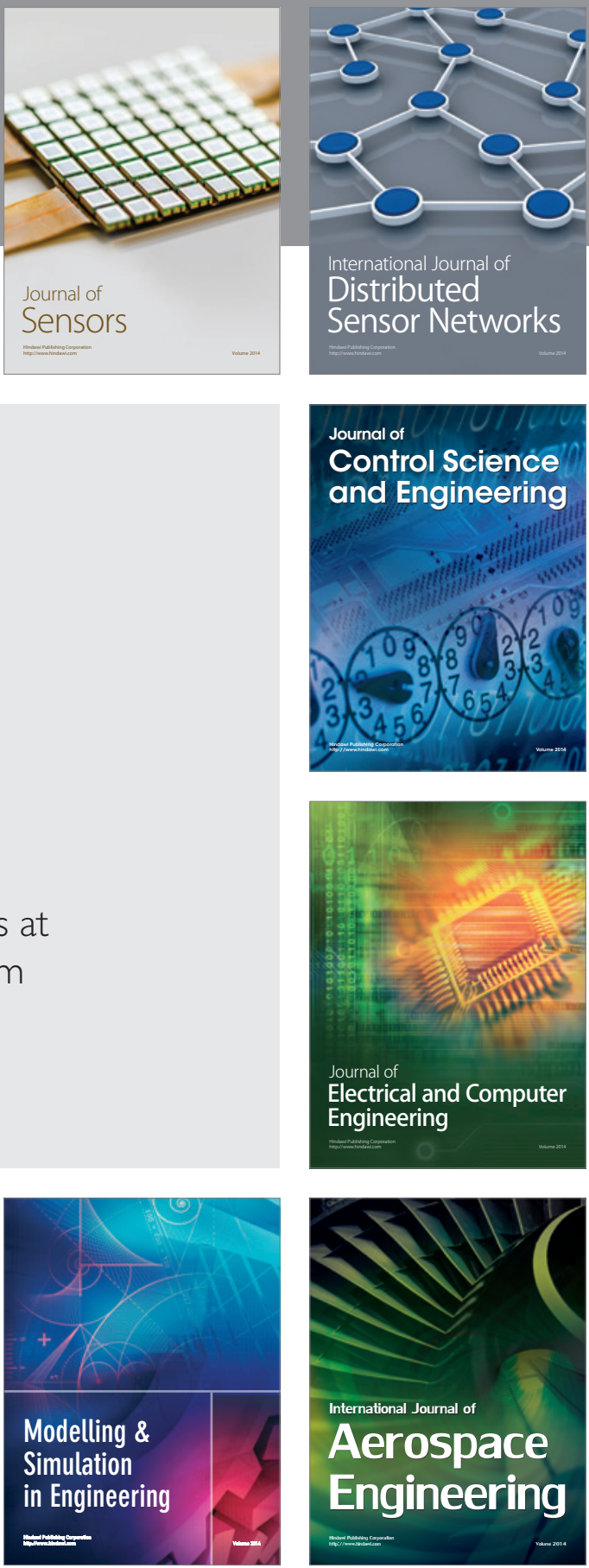

Journal of

Control Science

and Engineering
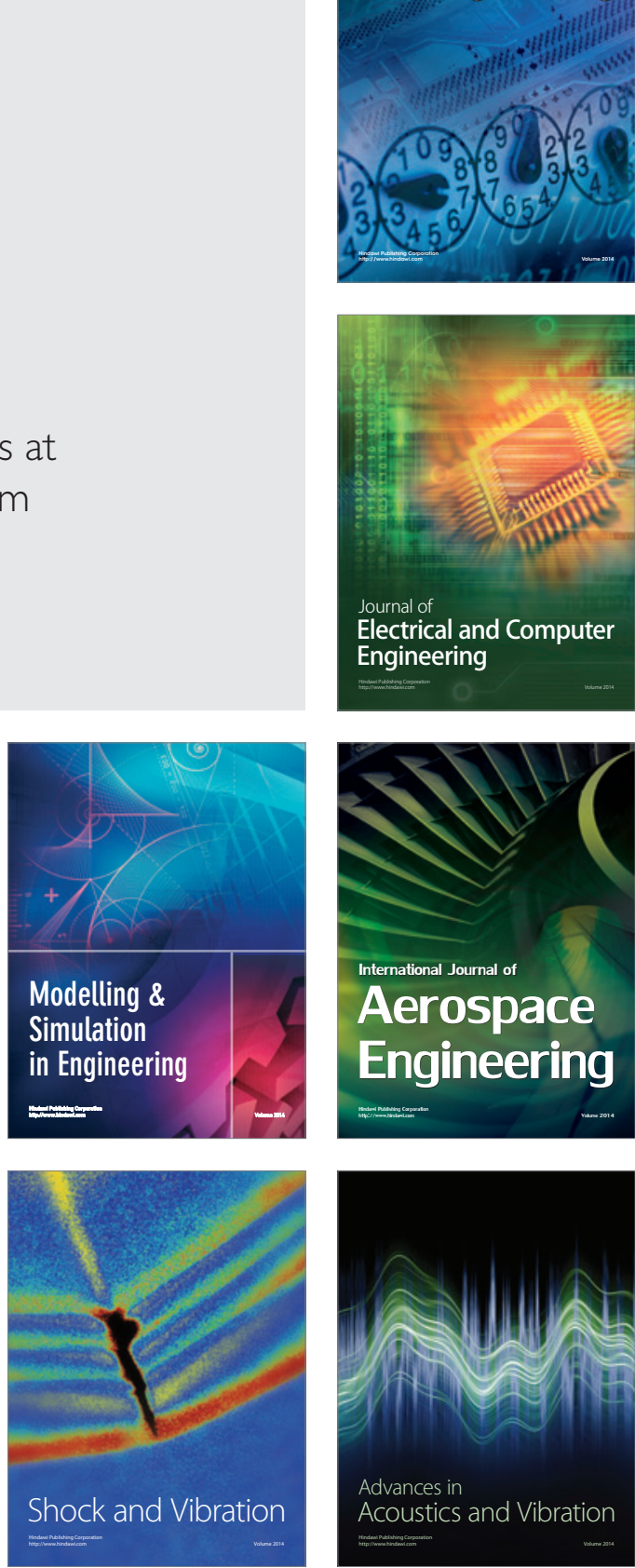